\title{
Optimizing Return to Learn Following a Sport-Related Concussion: A Quality Improvement Project
}

\author{
Dawn Ranns, DAT, ATC1,2 \& Tamara Valovich McLeod, PhD, ATC, FNATA2,3 \\ 'Limestone College, Gaffney, SC; ${ }^{2}$ Athletic Training Programs, and ${ }^{3}$ School of Osteopathic Medicine in Arizona, A.T. Still University, \\ Mesa, AZ
}

\begin{abstract}
Sport-related concussion (SRC) has been at the forefront of the sports medicine literature and media; however only recently has return to learn (RTL) been recognized as an important piece of a concussion management plan (CMP). A student's successful transition back to the classroom following SRC depends on the support, resources, and effective communication among the multidisciplinary team. This project focused on the assessment of current faculty knowledge, attitudes, and beliefs about concussion, the development of an RTL policy, and implementation of educational resources at a Division II institution. This project ran for 6 months, using 2 cycles of the plan, do, study, act (PDSA) methodology. An initial survey demonstrated faculty have a poor understanding of the behavioral and emotional signs and symptoms of concussion and that there was insufficient communication regarding student-athletes with concussion between faculty, staff, student-athlete, and administration. Initially, a RTL plan was developed and added to the existing concussion management plan (CMP), followed by the formation of a multidisciplinary concussion management plan (CMT). Finally, a one time in-person concussion education presentation was provided to faculty. Quantitative results from the post survey and semi-structured face-to-face interviews revealed improved communication among CMT members. One-hundred percent of faculty believed the brochure and presentation were helpful when managing a student with SRC. Faculty felt more knowledgeable and confident about academic adjustments and communicating with the CMT. Similarly, qualitative results from the in-person interviews with 8 faculty members revealed knowledge, confidence, and communication greatly improved; however, participants recommend additional education and a faculty resource page for concussion materials. This project demonstrated improvement in communication and efficiency in notifying faculty following injury minimizing time lag in academic adjustments. The RTL policy and faculty concussion education represents a simplistic, sustainable resource that could be replicated to other colleges.
\end{abstract}

Key Phrases

Policy and Procedure Development, Risk Management Mitigation, Collegiate and University Patient Population, Sport-related concussion, Return-to-Learn

Copyright (C) Indiana State University

ISSN Online 2577-8188
Correspondence

Dr. Tamara C. Valovich McLeod, A.T. Still University, 5850 E. Still Circle, Mesa, AZ 85206.

E-mail: tmcleod@atsu.edu

Twitter: @TamaraCVMcLeod

Full Citation

Ranns D \& Valovich McLeod TV. Optimizing Return to Learn Following a Sport-Related Concussion: A Quality

Improvement Project. Clin Pract Athl Train. 2019;2(3):1-15. https://doi.org/10.31622/2019/0003.1.

Submitted: May 23, 2019 Accepted: July 23, 2019

\section{CURRENT MODEL}

In 2017, the Center of Disease Control reported the incidence of sport-related concussion (SRC) as 2.5 million a year. ${ }^{1}$ This injury is most common in persons ages 15-24 with a prevalence rate ranging from 16-24\%. ${ }^{2}$ Although SRC management has significantly improved in the last decade, return to learn (RTL) is a relatively new piece to concussion recovery. Presently, only Division I institutions are required to submit a formal written concussion management plan (CMP) to the NCAA that includes both RTL and return to play criteria (RTP). To date, RTL protocols have been based on limited consensus driven empirical data and their effectiveness and clinical implementation has not been widely assessed.

This quality improvement project took place at a small private college, with an undergraduate enrollment of 2,595 students and approximately 850 student-athletes. The college is located in a suburban area that sponsors intercollegiate athletics at the NCAA Division II level. With large roster sizes, the addition of several new sports in the last five years, and a number of at risk sports including football, men's and women's soccer, men's and women's basketball, wrestling, acrobatics and tumbling, and men's and women's lacrosse, there was an increase number of 
reported SRC. In 2015-2016 there were 14 reported SRC, 2016-2017 12 reported SRC, 2017-201836 reported SRC, and 2018-2019 58 reported SRC's. In the previous CMP, when a student-athlete suffered a concussion, the athletic training staff notified the academic dean who then informed the student-athlete's professors a concussion had occurred; however, communication was often delayed or omitted either by athletic training staff or by an academic dean's office.

Collegiate student-athletes often identify themselves directly by their achievements on the field as well as in the classroom, therefore the faculty perception is vital in identifying the recovery from SRC. ${ }^{3}$ Faculty have the ability to positively or negatively impact a student's recovery depending on whether they will provide classroom support. The willingness of the faculty may be subjective by their preexisting knowledge of concussion, cognitively, physically, and behaviorally, and their beliefs about concussion.

While there is some evidence to suggest that short-term academic dysfunction occurs following sport-related concussion, ${ }^{4-7}$ these seem to resolve and not impact long-term academic outcomes, as reported through end of year grade point average. ${ }^{8}$ Specifically, Wasserman et al ${ }^{5}$ noted higher academic dysfunction scores in the initial week following concussion compared to peers with extremity injuries and Swanson et al ${ }^{7}$ reported academic difficulty among students with vision symptoms, hearing difficulty, and concentration issues. 7,9 Furthermore, surveys of student-athletes found that $27-90 \% 5$ of students and parents reported difficulty completing homework or classwork during the recovery time following concussion. ${ }^{5}$ When recovery is prolonged, there is a greater impact on perceived health status, with adolescent athletes reporting deficits in healthrelated quality of life related to school and cognitive functioning. ${ }^{10}$

During this quality improvement project the athletic training staff noticed once an initial e-mail was sent to an academic dean following a SRC there was no further communication with anyone about the academic performance of the student-

Copyright $(\subseteq$ Indiana State University ISSN Online 2577-8188 athlete. During the 2017-2018 academic year there were 36 SRC reported to the athletic training staff. Thirty-three percent $(n=12 / 36)$ of student-athletes became ineligible for their sport during the recovery semester and $72 \%(n=$ $26 / 36$ ) had a decrease in grade-point-average from Fall 2017 to Spring 2018. Sixteen percent $(n=6 / 36)$ of student-athletes were placed on academic suspension or withdrew from the institution. This data is consistent with the literature. 5,11 Over the course of the year, no faculty reached out to athletic training staff concerning a student's concussion or classroom needs. In addition, in reviewing the college policy for concussion management there was no information provided regarding RTL. Therefore, an initial survey was conducted of the college faculty in regard to understanding of concussion.

When the faculty were surveyed, $40 \%$ ( $n=$ $22 / 53$ ) of respondents never received notification when a student-athlete they taught was diagnosed with an SRC (Table 1). This lack of communication between faculty, administration, and/or healthcare providers does not follow best practices. In addition, student-athletes seldom received guidance and resources upon returning to the classroom nor does a healthcare provider follow-up with the student-athletes to assess progress in the classroom. Faculty perception of student's class attendance, quality of class participation or attentiveness, effort put forth on exams and assignments as well as not knowing a student has suffered an SRC could affect the recovery and the academic success of students. Therefore, this quality improvement project focused on the assessment of current faculty knowledge, attitudes, and beliefs about concussion, the development of a RTL policy, and implementation of educational support to all stakeholders involved with the management of a student-athlete following SRC. 
Table 1. Faculty Demographics Baseline Survey

\begin{tabular}{|c|c|c|}
\hline & $\mathbf{N}$ & $\%$ \\
\hline \multicolumn{3}{|l|}{ Gender $(n=52)$} \\
\hline Male & 21 & 40 \\
\hline Female & 26 & 50 \\
\hline Did not respond & 5 & 10 \\
\hline \multicolumn{3}{|l|}{ Age (years) $(n=42)$} \\
\hline $20-29$ & 5 & 12 \\
\hline $30-39$ & 10 & 24 \\
\hline $40-49$ & 10 & 24 \\
\hline $50-59$ & 9 & 23 \\
\hline $60-69$ & 6 & 14 \\
\hline $70-79$ & 1 & 2 \\
\hline \multicolumn{3}{|l|}{ Highest Level of Education ( $n=52$ ) } \\
\hline Bachelor's degree & 3 & 6 \\
\hline Master's degree & 24 & 50 \\
\hline Doctoral degree & 23 & 46 \\
\hline \multicolumn{3}{|l|}{ Years of Teaching Experience $(n=43)$} \\
\hline 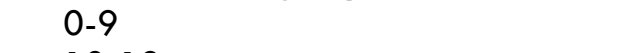 & 17 & 40 \\
\hline $10-19$ & 12 & 28 \\
\hline $20-29$ & 6 & 14 \\
\hline $30-39$ & 4 & 9 \\
\hline $40+$ & 1 & 2 \\
\hline \multicolumn{3}{|l|}{ Level of Schooling Taught* $(n=50)$} \\
\hline Undergraduate & 33 & 66 \\
\hline Post-baccalaureate - Master's level & 7 & 14 \\
\hline Post-baccalaureate - Doctoral level & 4 & 8 \\
\hline Not a teacher & 5 & 10 \\
\hline \multicolumn{3}{|l|}{ Academic Division $(n=49)$} \\
\hline Arts and Letters & 18 & 37 \\
\hline Social and Behavioral Science & 11 & 23 \\
\hline Natural Sciences & 10 & 20 \\
\hline Professional Studies & 6 & 12 \\
\hline Education and Physical Education & 4 & 8 \\
\hline \multicolumn{3}{|l|}{ Additional Roles Filled $(n=24)$} \\
\hline Academic Advisor & 21 & 88 \\
\hline Dean & 1 & 4 \\
\hline Department Chair & 6 & 25 \\
\hline Coach & 1 & 4 \\
\hline School Counselor & 1 & 4 \\
\hline
\end{tabular}

*Some Faculty Have Taught in Multiple Levels

\section{PDSA CYCLE}

Initially the author assessed the college faculty through the use of the University Faculty Knowledge, Attitudes, and Beliefs about Academic Adjustments for Students with Concussion survey to identify gaps in faculty knowledge about concussion and the academic adjustments. The survey is a modification from the validated beliefs, attitudes, and knowledge of pediatric athletes with concussion for (BAKPAC-AT). ${ }^{12}$ Written permission was given from the original authors of the survey. The survey was available to the faculty for 19 days, April 23 to May 9, 2018. Following the completion of the survey the investigator analyzed the survey data to identify problems with the current system to facilitate the first PDSA cycle.

The project team consisted of one author, who was a full-time faculty member of the institution and the faculty athletic representative, with perspectives of key figures academically with the faculty and athletically with the athletic department. Following the assessment of the survey the plan was three-fold: 1. Develop a standardized institution CMP, 2. Develop a multidisciplinary CMT, and 3. Disseminate the results of the baseline survey and implement concussion education to the faculty. Following the development of standardized form for return to learn, a one-time concussion education presentation was developed for faculty, athletic staff, athletic training staff, student-athletes and the medical director for athletics. For the purposes of this QI project only faculty were assessed following the presentation. A cause and effect diagram illustrated in Figure 1 was constructed based on the investigators' assessment of faculty knowledge from the baseline survey. A process diagram was developed to capture the current 
Figure 1. Cause and Effect ("Fishbone") Diagram

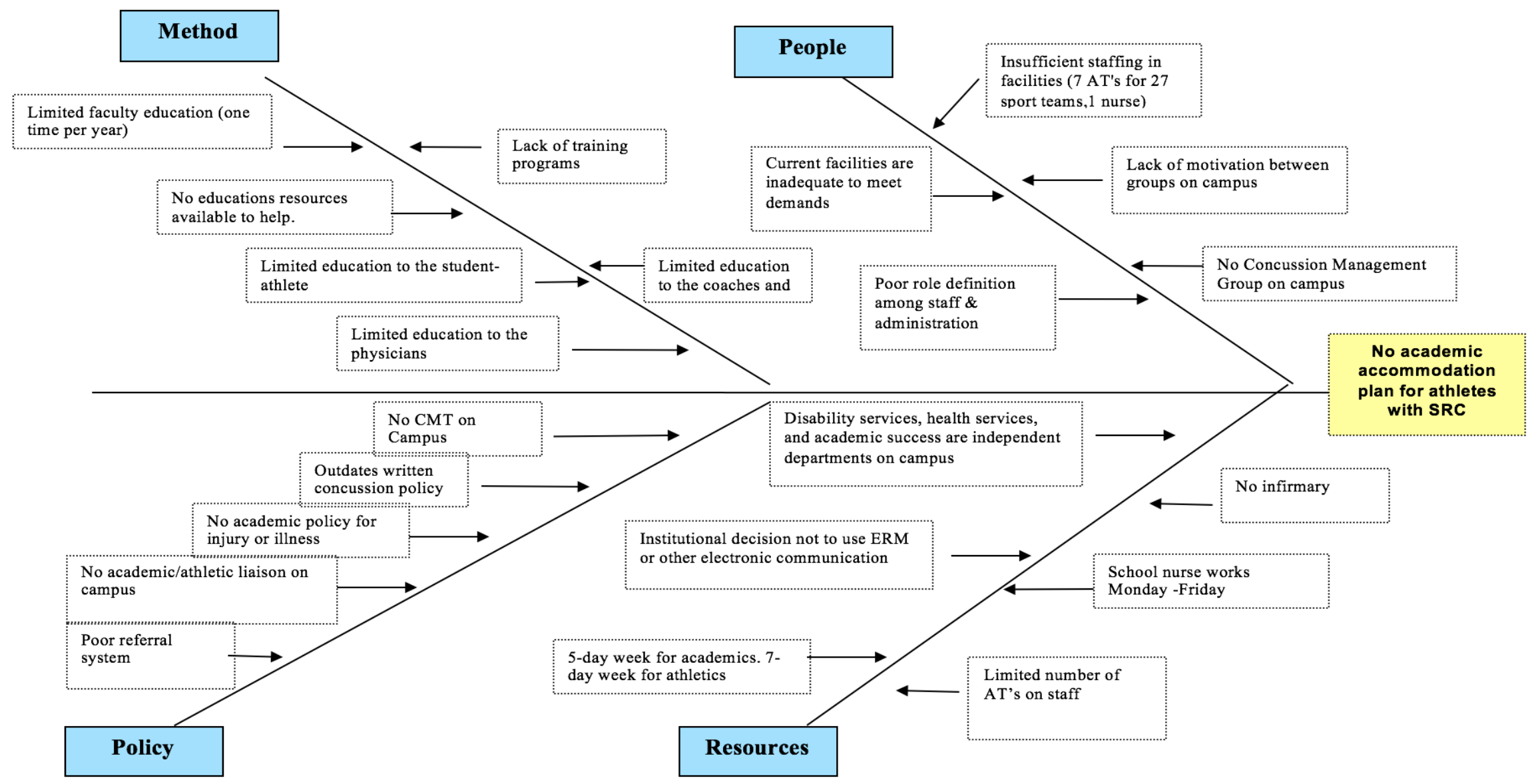


concussion management procedure for a studentathlete who suffers a SRC. An additional process diagram was developed including the ultimate goal of operation following a SRC and the RTL that is currently used when a student-athlete suffers a concussion. Both current and future institutional process diagrams are displayed in Figure 2 and Figure 3. Implementation of the new flow chart in August 2018 has made the process more efficient by streamlining a student-athletes RTL and RTP, ultimately eliminates faculty's need to reach out to someone at the intuition when a student-athlete returns to the classroom.

It was clear by the initial assessment that faculty knowledge on concussion, academic adjustments, and collaboration between faculty and staff is limited. Most faculty recognized a concussion is serious; however, they lacked knowledge about cognitive rest and limitations following a SRC or the ability to provide appropriate academic adjustments for students. It was hypothesized improving faculty communication with various stakeholders and identifying their role on the CMT and providing academic adjustments for students, faculty would be more likely to provide assistance

Figure 2. Previous SRC Flowchart

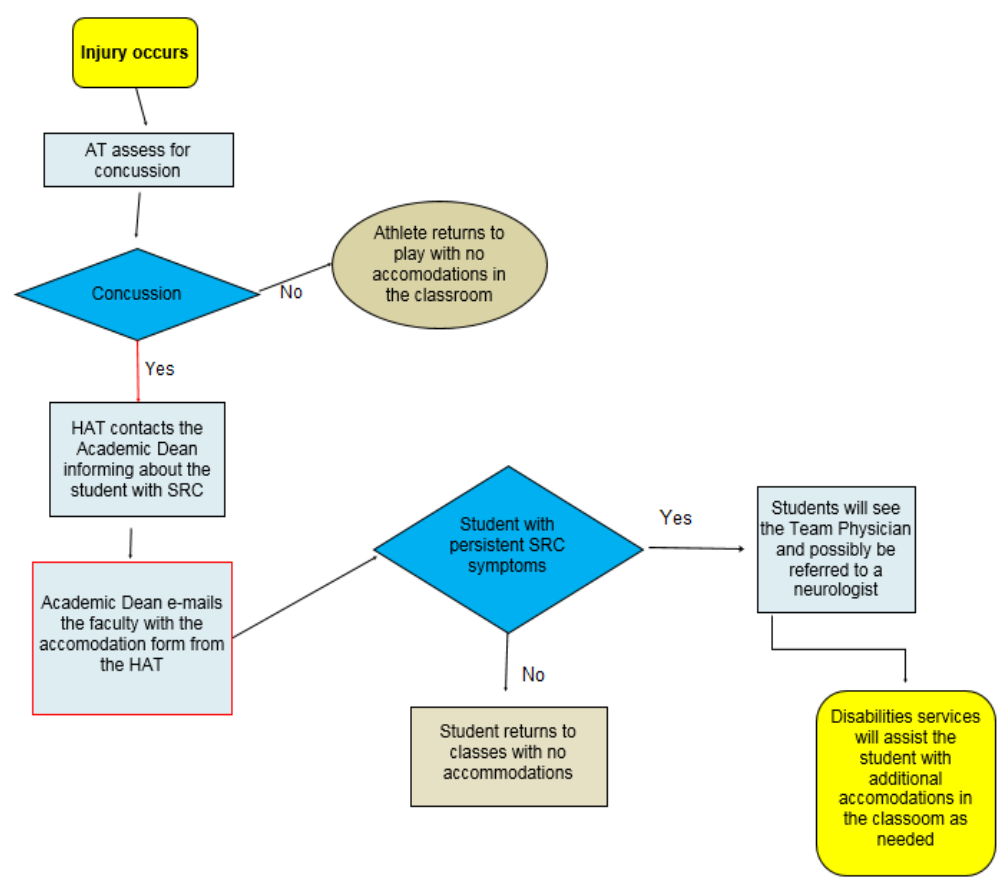

Copyright $(C)$ Indiana State University ISSN Online 2577-8188 to students and student overall success will improve when returning to the classroom (Figure 1).

\section{PDSA CYCLE 1}

Following the baseline data collection from the initial University Faculty Knowledge, Attitudes, and Beliefs about Academic Adjustments for Students with Concussion survey and the cause and effect diagram it was identified that faculty lacked overall basic knowledge on concussion and applicable academic adjustments for students returning to the classroom following a SRC.

\section{Plan}

In August 2018, all faculty attended a single concussion education presentation and received a brochure about the new RTL policy for studentathletes following a SRC. During the Fall 2018 semester all student-athlete's suffering a SRC reported to the CMT to be assessed for their individual RTL plan. Faculty were informed via email of student-athletes who suffered a SRC within 24-hours of injury on the institutions concussion awareness form. Student-athletes reported to the CMT bi-weekly for re-assessment until they are discharged from any RTL classroom adjustments. Faculty received updated information via e-mail within 24-hours following each student-athlete's appointment with the CMT as well as a discharge letter when the student no longer required adjustments in the classroom. From September to October 2018 faculty completed a post survey. Pre- and post-survey results were then compared to asses any changes in the faculty's knowledge, attitudes, and beliefs of SRC and academic adjustments.

Do

The initial intervention incorporated a single concussion education presentation and brochure to the faculty that included information related to 1 . Basic concussion knowledge, 2. Appropriate academic adjustments for the classroom, 3 . Personnel involved in the multidiscipline CMT, and 4. The eight stages of the RTL policy for the institution. In August 2018, all faculty at the 
institution were presented the concussion education and a concussion awareness brochure. From September 25 - October 12, 2018 faculty completed the survey with modifications to the original University Faculty Knowledge, Attitudes, and Beliefs about Academic Adjustments for Students with Concussion survey to determine if change occurred. The results were analyzed to evaluate the effectiveness of the educational presentation and brochure.

\section{Study}

A total of 157 faculty were e-mailed the survey, 45 responses, and 24 individuals completed the entire survey for a $15 \%$ response rate. Generalized analysis of results considered only the results of the 24 complete surveys; however, individual question analysis assessed all available information. All faculty agreed the educational presentation was beneficial. A majority of faculty would prefer a variety of alternative education mode such as links associated to concussion, recorded webinars, live webinars, and in-person presentations. Oddly, 43.48\% ( $n=10 / 23$ ) of faculty would prefer not to receive any more information on concussion.

Faculty knowledge of symptoms associated with concussion improved in 11 of 22 symptoms, only 4 symptoms scored worse on the post survey. Symptoms related to emotions conveyed the greatest improvement of all symptoms. Faculty recognition of signs and symptoms of concussion is illustrated in Figure 4.

Faculty knowledge on prevention, physical and cognitive sign and symptoms, treatment and management, RTL, and RTP increased in all categories. Results of improvement for physical and cognitive signs and symptoms and RTL are illustrated in Figure 5. More faculty were extremely knowledgeable and moderately knowledgeable in these areas than found in the baseline assessment. Faculty knowledge about concussion and a better understanding of academic adjustments were the greatest improvement. When asked how often the care of concussed student-athletes were discussed between the faculty and the CMT 65\% ( $n=$ $17 / 26)$ of faculty reported always, $23.08 \%$ ( $n=$ 6) almost always, and $26.92 \%(n=7)$ often. This was a significant increase from $33 \%(n=11 / 27)$ of faculty reporting in the same categories. Communication improved between the faculty and the CMT. Faculty indicated that they received information on injured or ill students more often in the post survey, $77 \%(n=22 / 24)$, than reported at baseline $36 \%(n=8 / 22)$ resulting in a $41 \%$ increase in communication.

Familiarity with academic adjustments also improved. Initial baseline results indicate that $9 \%$ ( $n=5 / 53$ ) of faculty were not familiar, $43.40 \%$ ( $n=23 / 53$ ) minimally familiar, $35.85 \%$ ( $n=$ $19 / 53$ ) were moderately familiar, and $11.32 \%$ were extremely familiar with academic adjustments. Post-survey results found all faculty ( $n=24$ ) were either moderately familiar $58 \%$ ( $n$ $=14 / 24)$ or extremely familiar $42 \%(n=10 / 24)$ with academic adjustments.

There was a 10\% increase of faculty who recognized the institution has an academic support team. Faculty were also more likely to recommend academic adjustments to a student after the educational presentation. At baseline 33\% ( $n=$ $17 / 53$ ) of faculty responded they rarely to never recommended academic adjustments; however; in the post-survey, all faculty $(n=23)$ responded they always, almost always, often, or sometimes recommend academic adjustments.

There continues to be a variety of responses in the post-survey when faculty $(n=16)$ were asked who is involved in the academic support team for concussion students. However, 100\% of faculty surveyed recognized the CMT was part of the academic support team. Some of the weakest areas of recognition were the nurse $44 \%$ ( $n=$ $7 / 16)$, team physician $25 \%(n=4 / 16)$, teachers and disability services each at $44 \%(n=7 / 16)$. Faculty still do not fully know who the point person is to manage academic adjustments. Percentages on the baseline and post-survey improved by $8 \%$, only raising the score to $52 \%$. This is an area that indicates further education and growth. 


\section{Act}

Over the course of the Fall semester there were 36 total SRC. With a large number of SRC in future PDSA cycles there needs to be more than one person in the CMT that facilitates concussion assessment following injury. Initial, follow-up, and discharge paperwork to the faculty was time consuming and difficult to keep up with. Allowing more individuals in the CMT to contribute to the assessment and documentation in the Fall 2019 semester will allow some of burden to be lifted and more efficient communication may occur. Continuing to educate the athletic trainers, coaches, and other healthcare providers on the institutions RTL policy will also improve awareness. In the Fall semester student-athletes who suffered a SRC were still going to study hall, film, athletic practices, and weight lifting. Continued education will improve faculty and staff awareness of student-athletes with increased symptoms during various activities and allow them to more confidently adjust activities that could hinder recovery.

\section{PDSA CYCLE 2}

\section{Plan}

Following the results of the post-survey the plan was to assess 8-10 faculty member's comfort and satisfaction with: 1 . The educational presentation, 2. The concussion awareness brochure, 3. The CMT, and 4. The eight stage RTL policy using a semi-structured face-to-face interview. The interview questions were a modification from the interview protocol used for the Perceived Outcomes of Web-based Modules Designed to Enhance Athletic Trainers Knowledge of Evidence Based Practice (Table 2). ${ }^{13}$ Written permission was given from the original author of the interview questions. The aim was to recruit 8-10 faculty members to achieve saturation. Faculty members were selected for an interview if they had one or more student-athletes who sustained a SRC in a course Fall 2018.

\section{Do}

There were 18 SRC reported August - October 2018 that impacted 28 individual faculty members at the institution. A total of 8 faculty members volunteered to be interviewed (males 3 , females 5). All faculty members were given pseudonyms to maintain participant anonymity. Demographics on the faculty interviewed are illustrated in Table 3.

The purpose of the in-person interview was to determine the effectiveness of an educational presentation and brochure on concussion management and academic adjustments following the RTL from a SRC. Specifically, the aim was to assess faculty perceptions of whether the implementation of educational presentation promoted immediate changes in a classroom.

\section{Study}

The results of the interviews revealed four underlining themes; 1 . The knowledge gain and transfer from the presentation and brochure, 2. Increased communication and positive impact for the students, 3. Barriers in implementing academic adjustments, and 4. Suggestions for future improvements.

Overall the faculty were pleased with the presentation and brochure. The majority thought that the education was eye opening when thinking about concussion and RTL. One faculty responded, "having the presentation in a handout so that individuals who are visual learners can follow along while the presentation is going can be helpful. Additionally, having the brochure available both in a paper format and a digital format to refer back to, whether that's an e-mail or on the website could be helpful for faculty for a quick reference." 
Figure 4. Baseline and post-survey faculty knowledge of concussion symptoms

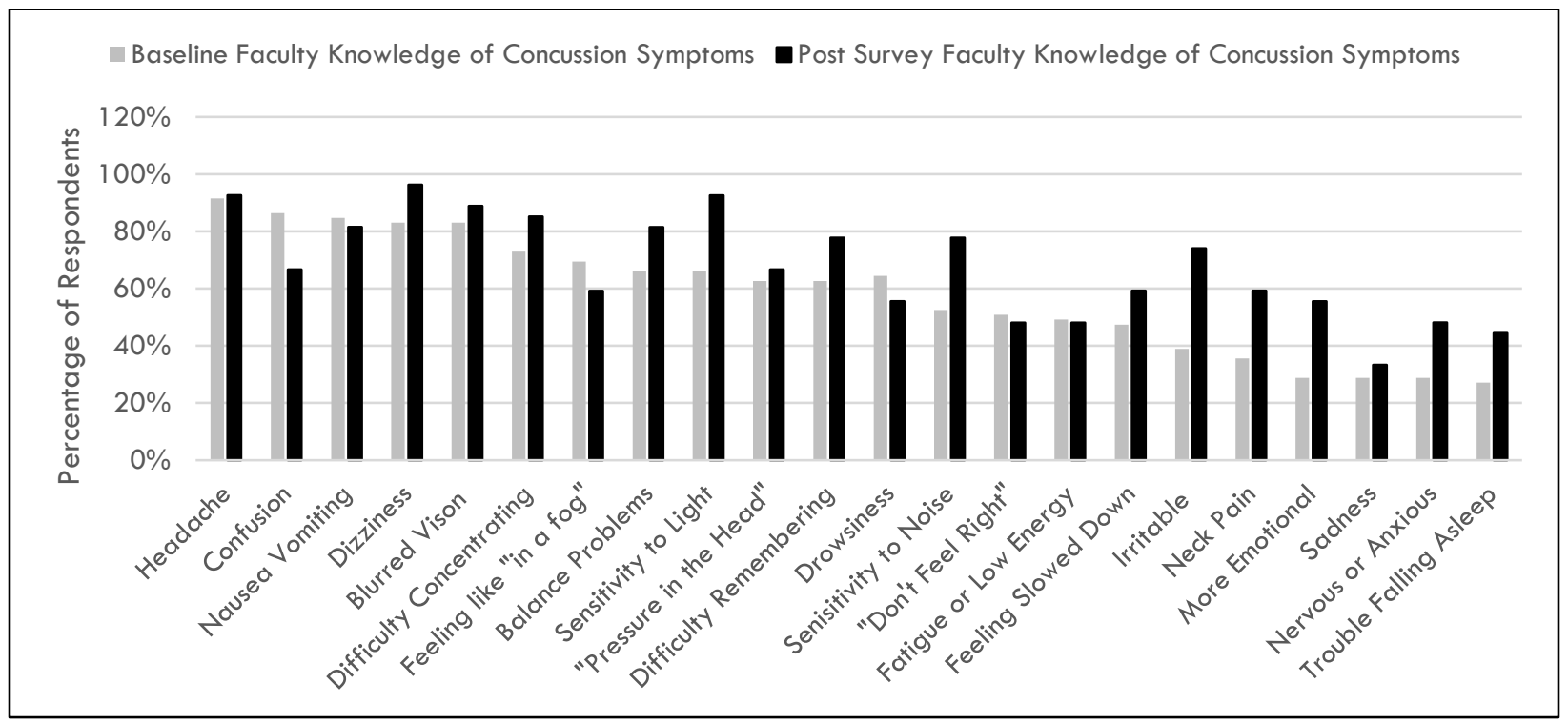

Figure 5. Knowledge of physical and cognitive signs and symptoms and return to learn at the initial survey and following the educational intervention.

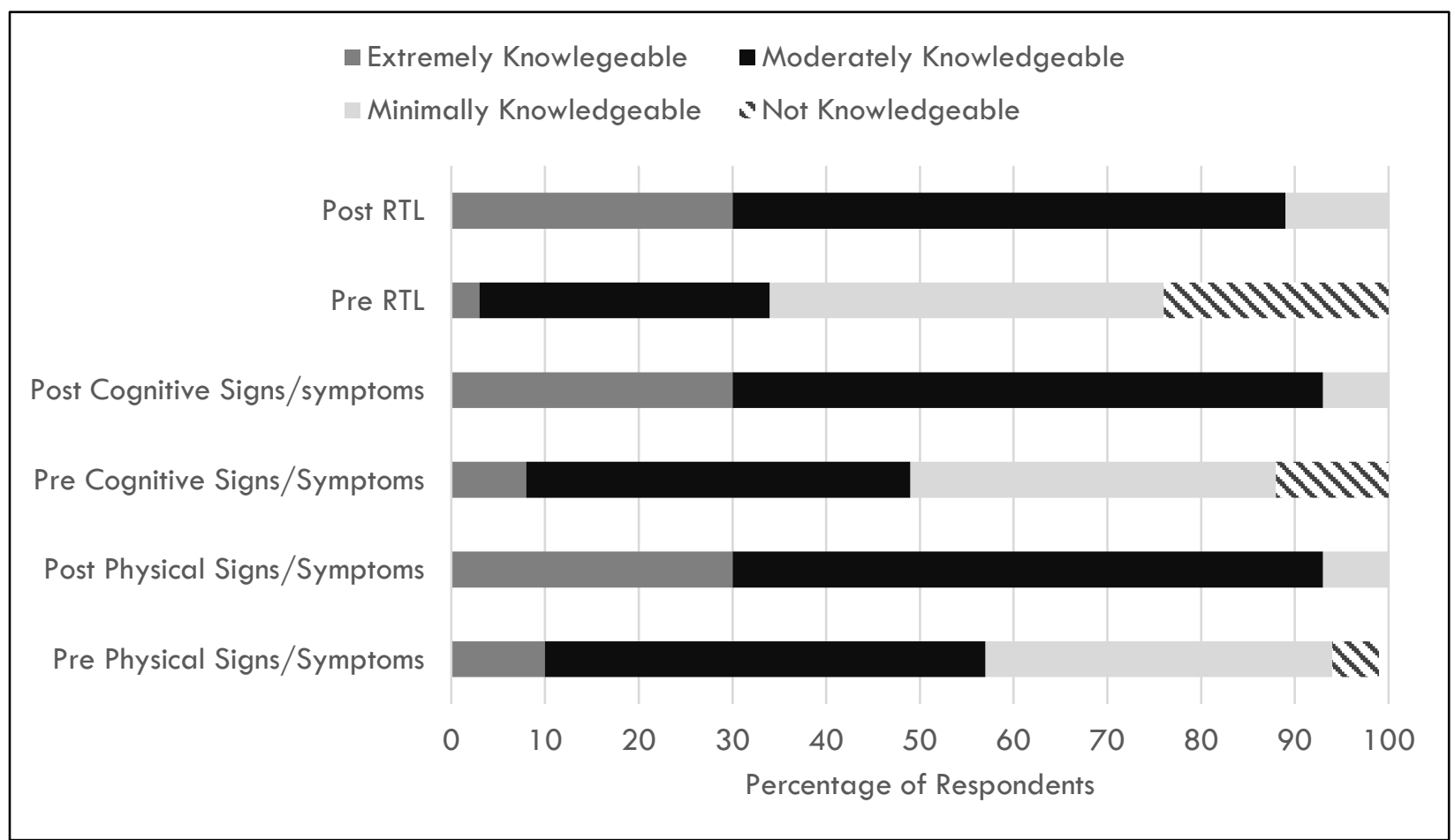


Table 2. Interview Protocol Questions With Probes

1. Tell me a little about your background as a faculty member?

2. In what ways, if any, do you feel the presentation and brochure can be improved?

3. Did the concussion presentation and brochure change your perception about concussion in any way?

4. Do you feel that the concussion presentation and brochure had a positive or negative impact when a student returned to the classroom with a concussion? Please explain.

5. What concepts, if any, did you take from the concussion presentation and brochure that you implemented in your classroom with students returning to school from a concussion?

a. Are there concepts you feel like you need more information on before you can implement?

b. Are there any barriers preventing you from implementing adjustments into your classroom?

6. Do you feel that the communication has improved between various personnel when a student in you class has sustained a concussion?

a. What about the return to learn process do you feel need to be improved?

b. Do you feel there are ways to further improve the communication between personnel and student?

c. Do you feel that you receive sufficient and timely information on the student who sustained a concussion as well as continued follow-up information throughout the process? d. Do you feel confident in the students Stage of RTL and the adjustments for the student each day?

e. Is there anything that you would improve or change in the RTL policy or communication?

7. Are there any questions or topics I have not asked about that you would like to discuss?

Overall a majority of the faculty agreed they were more comfortable with making decisions in the classroom when one or more students returned following a SRC. The educational presentations made them more aware of the symptoms a student could experience in the classroom and the role of the faculty necessary for student with accommodations. Faculty recognized that small adjustments to the classroom such as; turning the

Copyright (C) Indiana State University

ISSN Online 2577-8188 florescent lights down, providing paper copies of the notes, and closing the door to decrease outside noise increased the student's attendance to class. One faculty states, "I think the biggest impact that l've benefited from is getting the update for each of my students so that if I have information that a student has to take short breaks, or if I need to dim the lights, or if a student has to wear sunglasses or a hat within the class to help them manage their symptoms."

Communication among medical personnel, faculty, staff, students, and administration was recognized as a barrier when students are injured or ill. Interview Question 6 focused on faculty perception of communication across the institution. All agreed that communication among faculty, the CMT, and students has increased this year. Faculty felt that students were being more proactive with their professors and notification of injury was being e-mailed with 24 hours of injury. Faculty were more aware of student injury and recognized the need to provide academic adjustments. Half the faculty agreed some sort of electronic information site would be helpful especially for faculty who only have 1 to 2 students return to their classroom following a SRC. One faculty agreed, "Communication has increased tremendously. We were getting nothing before. I didn't know who had a concussion. The new formula for getting those periodic reports is much improved." Most faculty agreed they were more aware of the student's injury and received timely updates on the students throughout the process; however, they were not confident about academic adjustments with all courses they teach and would like to see more information related to RTL.

All faculty members agreed the educational presentation and brochure had a positive effect on their ability to recognize the seriousness of concussion. One faculty responded "it helped more faculty members to realize that they needed to take concussion seriously. I think it helped to realize more of the symptoms that go with concussions, as well as some of the signs to look for. What I really appreciate is the increase in communication that's come from the CMT because now I know more about those students that have 
Table 3. Participants Demographics

\begin{tabular}{lcccc}
\hline $\begin{array}{l}\text { Participant } \\
\text { Pseudonym }\end{array}$ & Sex & $\begin{array}{c}\text { Experience as a } \\
\text { Faculty Member } \\
\text { at Limestone }\end{array}$ & Primary Teaching Role & Method of Instruction \\
\hline Julian Bailey & Male & 1 year & Literacy library & On-line Classroom \\
Lora Lane & Female & 7 years & Computer Science & On-line/Traditional \\
Vicky Perkins & Female & 16 years & Athletic Training & Traditional Day \\
Cheryl Raines & Female & 1 year & English & Traditional Day \\
Eva Moore & Female & 5 years & English & Traditional Day \\
Sara Martin & Female & 18 years & Biology/HS & On-line/Traditional \\
Alex Lamb & Male & 6 years & Strength \& Conditioning & Traditional Day \\
\hline
\end{tabular}

concussions as well as how they are progressing through the stages of RTL and RTP."

Half the faculty interviewed found at least one barrier to implementing academic adjustments in a classroom this year when a student returned following a SRC. Non-traditional courses that included science labs, discussion classes, activity classes, and on-line classes experienced that most difficulty with providing the student with academic adjustments necessary to attend classes.

Faculty agreed the educational presentation and brochure was a great first step to student success in the RTL following a SRC. However, the majority of faculty interviewed agreed it would be beneficial to have some sort of faculty resource page online they could refer to periodically.

\section{Act}

The faculty interviews revealed that communication had improved however, faculty are still not comfortable with classroom adjustments. Barriers to implementation included limited time and not knowing how to provide adjustments for course that are not taught as traditional day classes. Improvements for future PDSA cycles will include education on additional resources available for faculty that teach nontraditional courses such as discussion class, on-line classes, and science labs.

\section{LESSONS AND LIMITATIONS}

During the 40 weeks of this QI project there were several changes occurring at the institution. The inauguration of a new president and a complete

Copyright (C) Indiana State University ISSN Online 2577-8188 football staffing change both took place mid-year in January 2018. Additionally, acrobatics and tumbling was added as a new NCAA sport for the Fall 2018 and the athletic training staff were in the process of transitioning from paper files and Sportswear to NExTT software system. One lesson that was learned was that the timing of the survey is extremely important to have a good response rate from the faculty. Unfortunately, the baseline survey was available to the faculty at a time when several other surveys were circulating through faculty e-mail. It also occurred at the end of the semester just before final exams.

Because faculty were not required to return to campus until the annual faculty staff meetings on August 16, 2018 the presentation was given after all Fall sport student-athletes had already been practicing. However, the presentation was held before the first traditional day courses started. Additionally, it was difficult to educate all faculty at one meeting because there are three methods of education at the institution; the traditional day program, on-line program, and off campus sites. Most of the student-athletes take courses in both the traditional day and on-line program. There were only a few problems with academic adjustments for the traditional day program in discussion based classes and biology lab. However, it was difficult to provide academic adjustments for students that took on-line course that required the student to use their cell phone or computer to complete all homework, assignments, projects, and exams for the course. This is an issue that is still not resolved especially when a studentathlete had prolonged symptoms beyond the twoweek period. 
Finally, faculty attendance at the concussion presentation and acceptance and implementation of the new RTL policy may be a limitation of this project. Academic freedom in higher education protects the faculty in the classroom. Faculty have the freedom to express their views through speech, written, or electronic communication without reprimand. Academic freedom also protects faculty and students from punishment for disagreeing with administrative policies or proposals. ${ }^{14}$ Faculty have the freedom to disagree with the new RTL policy for studentathletes returning to the classroom following a SRC. Fortunately, concussion and $\mathrm{mTBI}$ fall under the Americans with Disabilities Act which also protect the student. ${ }^{15}$ Future education will provide faculty with additional long-term effects from SRC and the importance in providing students with academic adjustments as they recover. However, because of the high volume of stunt-athletes at the institution some faculty may become frustrated with the increased workload of accommodating a large number of concussed students.

\section{CONCLUSIONS}

Return to learn is still a relatively new addition to the concussion management plan with limited empirical evidence to support it. Although it is unclear if concussion education has sustainable long-term effects on knowledge, attitude, and beliefs, there have been short-term preliminary results of knowledge gains. This QI project identified a lack of a standardized CMP that included RTL. This QI project identified a lack of a standardized CMP that included RTL. This problem has been identified in the literature at other NCAA institutions and has led to an increase awareness and recognition for the importance of cognitive rest following injury as well as quick notification of injury and academic adjustments for successful student outcomes upon return to class. ${ }^{3}$ At the college, this has hindered the development of a CMT, communication and notification to key stakeholders following injury, education about concussion to the staff, faculty, and administration, and proper academic accommodations necessary for student success. A University Faculty
Knowledge, Attitudes, and Beliefs about Academic Adjustments for Students with Concussion survey was used initially to determine gaps with the faculty. Following the survey results a new CMP was drafted including a RTL plan. These changes were implemented in Fall 2018. In addition, an educational concussion presentation and brochure was provided to each faculty member. In October, 8 faculty members were interviewed to assess effectiveness of the educational concussion presentation and the user friendliness of the brochure and RTL plan in the classroom. Finally, a post-survey was provided to determine improvements in the QI project.

Return-to-learn is a relatively new term in concussion management of student-athletes. This QI project provides insight related to faculty knowledge, attitude, and beliefs about SRC and suggests that a short-term education intervention can influence the level of communication across the campus. By providing an effective policy and line of communication and minimal changes to the environment we saw a culture shift among studentathlete's faculty, and administration relationships related to classroom support. We are incorporating the new policy into daily practice and are sharing ideas and methods via e-mail, inperson, and during faculty meetings. During the 2018-2019 academic year there were a total of 58 SRC. These student-athletes will to be reassessed in the 2019-2020 academic year and monitored for any classroom support still needed. This QI project will continue to educate faculty on SRC and student-athletes classroom accommodated. Further investigation could include evaluation of will look at improving student-athlete, athletic staff, and medical professional knowledge, attitude, and belief of SRC to improve the CMP with regards to the RTP and student success.

\section{REFERENCES}

1. McAvoy K, Eagan-Johnson B, Halstead M. Return to learn: Transitioning to school and through ascending levels of academic support for students following a concussion. 
NeuroRehabilitation. $\quad 2018$ (Preprint):1-6. https://doi.org/10.3233/NRE-172381

2. Heaps A. Knowledge and experience of inservice, secondary and post-secondary teachers on mild traumatic brain injuries: Return to learning in the classroom. 2018.

3. Webbe FM. The Handbook of Sport Neuropsychology. New York: Springer Publishing Company; 2011.

4. Moser RS, Schatz P, Jordan BD. Prolonged effects of concussion in high school athletes. Neurosurgery. 2005;57(2):300-306. https://doi.org/10.1227/01.neu.00001666 63.98616.e4

5. Wasserman EB, Bazarian JJ, Mapstone $M$, Block $R$, van Wijngaarden E. Academic dysfunction after a concussion among US high school and college students. Am J Public Health. 2016;106(7):1247-1253. https://doi.org/10.2105/AJPH.2016.30315 $\underline{4}$

6. Ransom DM, Vaughan CG, Pratson L, Sady MD, McGill CA, Gioia GA. Academic effects of concussion in children and adolescents. Pediatrics. 2015;135(6):1043-1050. https://doi.org/10.1542/peds.2014-3434

7. Swanson MW, Weise KK, Dreer $L E$, et al. Academic difficulty and vision symptoms in children with concussion. Optom Vis Sci. 2017;94(1):60-67.

https://doi.org/10.1097/OPX.000000000 $\underline{0000977}$

8. Russell K, Hutchison MG, Selci E, Leiter J, Chateau D, Ellis MJ. Academic outcomes in high-school students after a concussion: A retrospective population-based analysis. PLoS One. 2016;11(10):e0165116. https://doi.org/10.1371/iournal.pone.0165 116

9. Erin B W, Zachary Y K, Scott L Z, Tracey C. Epidemiology of sports-related concussions in national collegiate athletic association athletes from 2009-2010 to 2013-2014: Symptom prevalence, symptom resolution time, and return-to-play time. Am J Sports Med.

2016(1):226. https://doi.org/10.1177/0363546515610 $\underline{537}$

10. McLeod TV, Bay RC, Lam KC, Valier ARS. The association between length of recovery following sport-related concussion and generic and specific health-related quality of life in adolescent athletes: a prospective, longitudinal study. J Head Trauma Rehabil. 2019;34(1):E1-E9.

https://doi.org/10.1097/HTR.0000000000 $\underline{000394}$

11. Williamson CL, Norte GE, Broshek DK, Hart $J M$, Resch JE. Return to learn after sportrelated concussion: A survey of secondary school and collegiate athletic trainers. J Athl Train.

2018. https://doi.org/10.4085/1062-6050-23417

12. Bacon CEW, Kay MC, McLeod TCV. Athletic trainers' roles and responsibilities regarding academic adjustments as part of the concussion-management process in the secondary school setting. I Athl Train. 2017;52(10):937-945. https://doi.org/10.4085/1062-605052.7.02

13. Welch CE, Van Lunen BL, Hankemeier DA, et al. Perceived outcomes of web-based modules designed to enhance athletic trainers' knowledge of evidence-based practice. J Athl Train. 2014;49(2):220-233. https://doi.org/10.4085/1062-605049.2.14

14. Poch RK. Academic Freedom in American Higher Education: Rights, Responsibilities and Limitations. ASHE-ERIC Higher Education Report No. 4. 1993.

15. Halstead ME, McAvoy K, Devore CD, Carl R, Lee $M$, Logan K. Returning to learning following a concussion. Pediatrics. 2013;132(5):948-957. https://doi.org/10.1542/peds.2013-2867 
Figure 3. Current SRC Flowchart

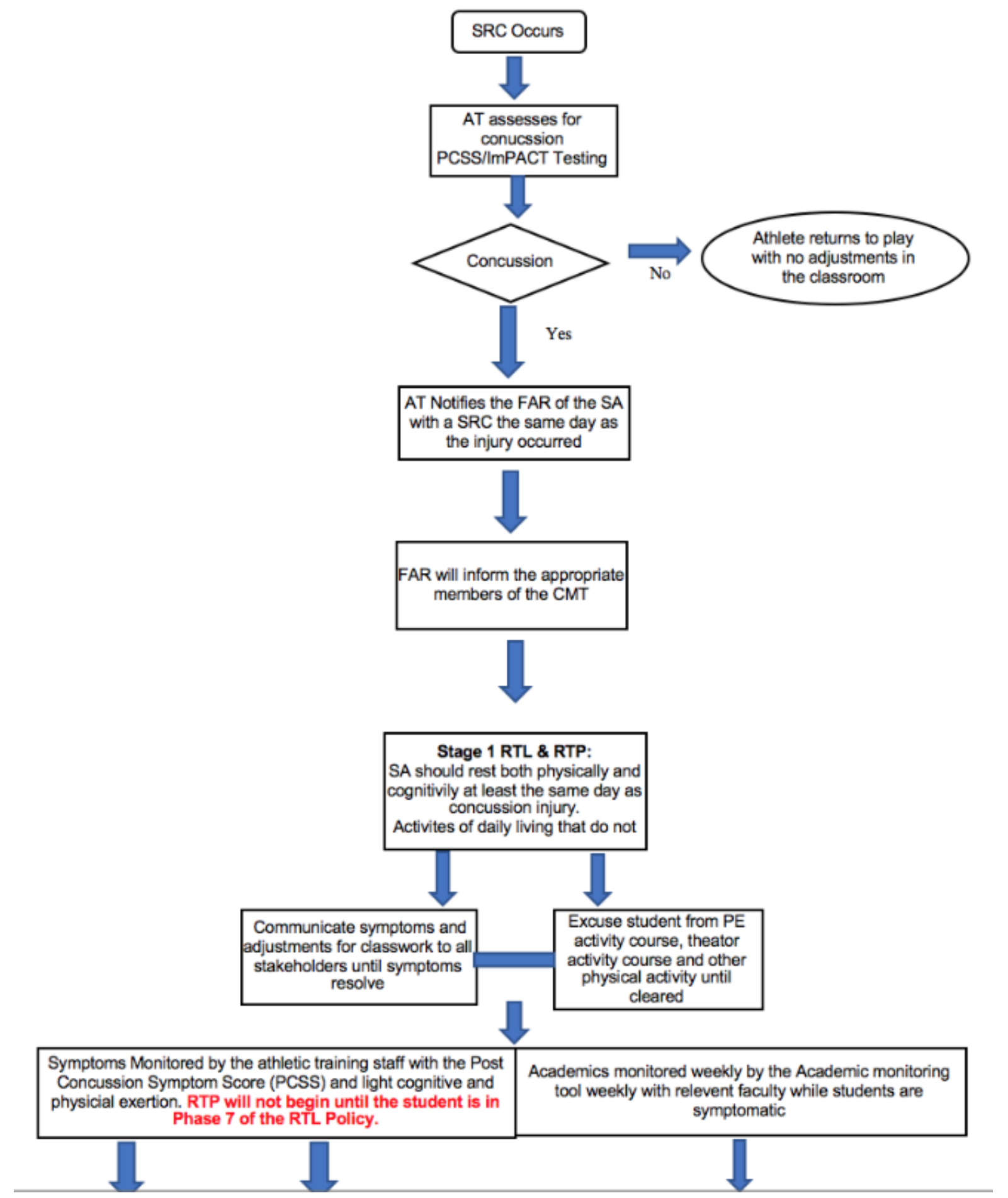


Figure 3. Current SRC Flow Chart (cont.)

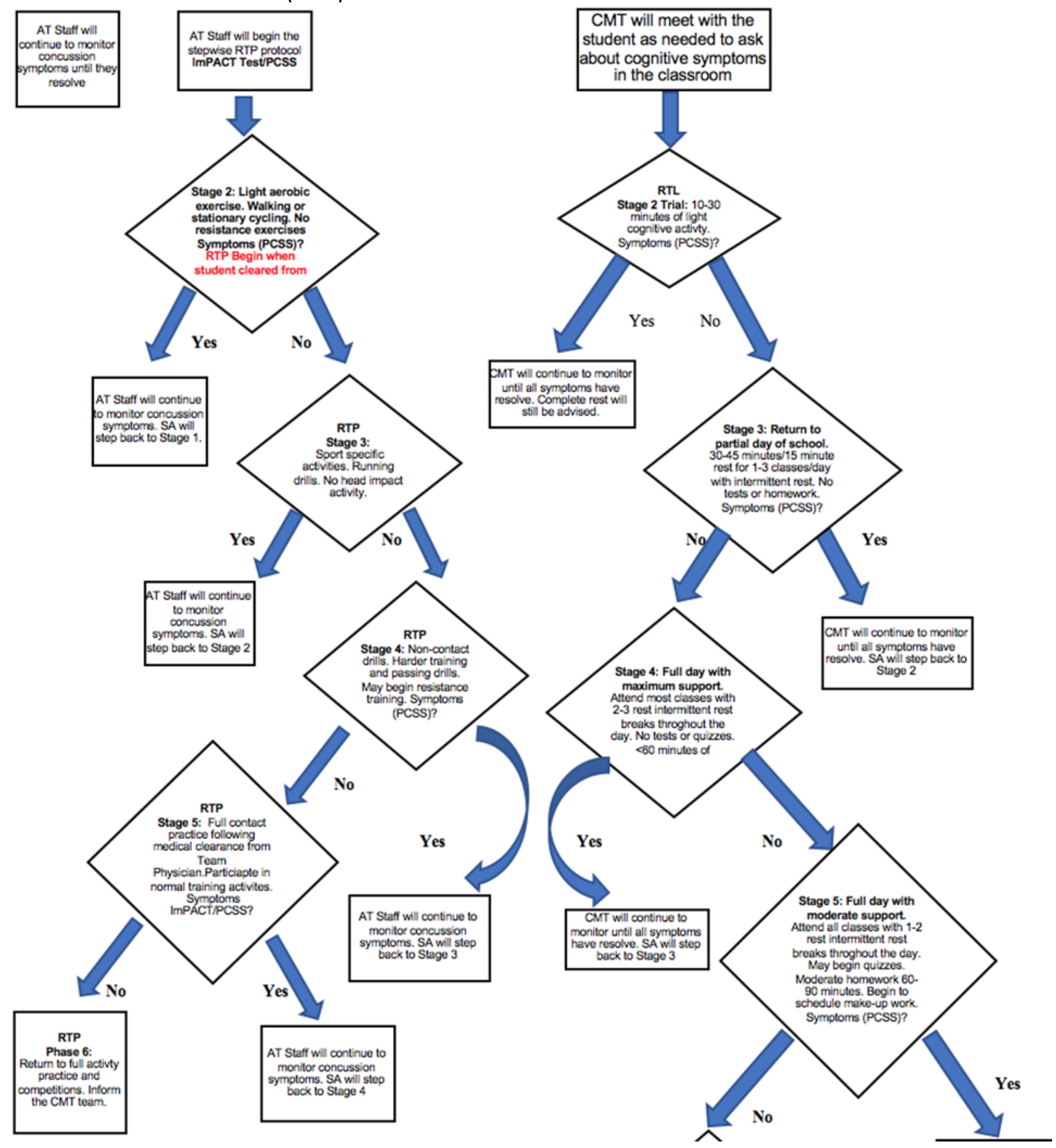


Figure 3. Current SRC Flow Chart (cont.)

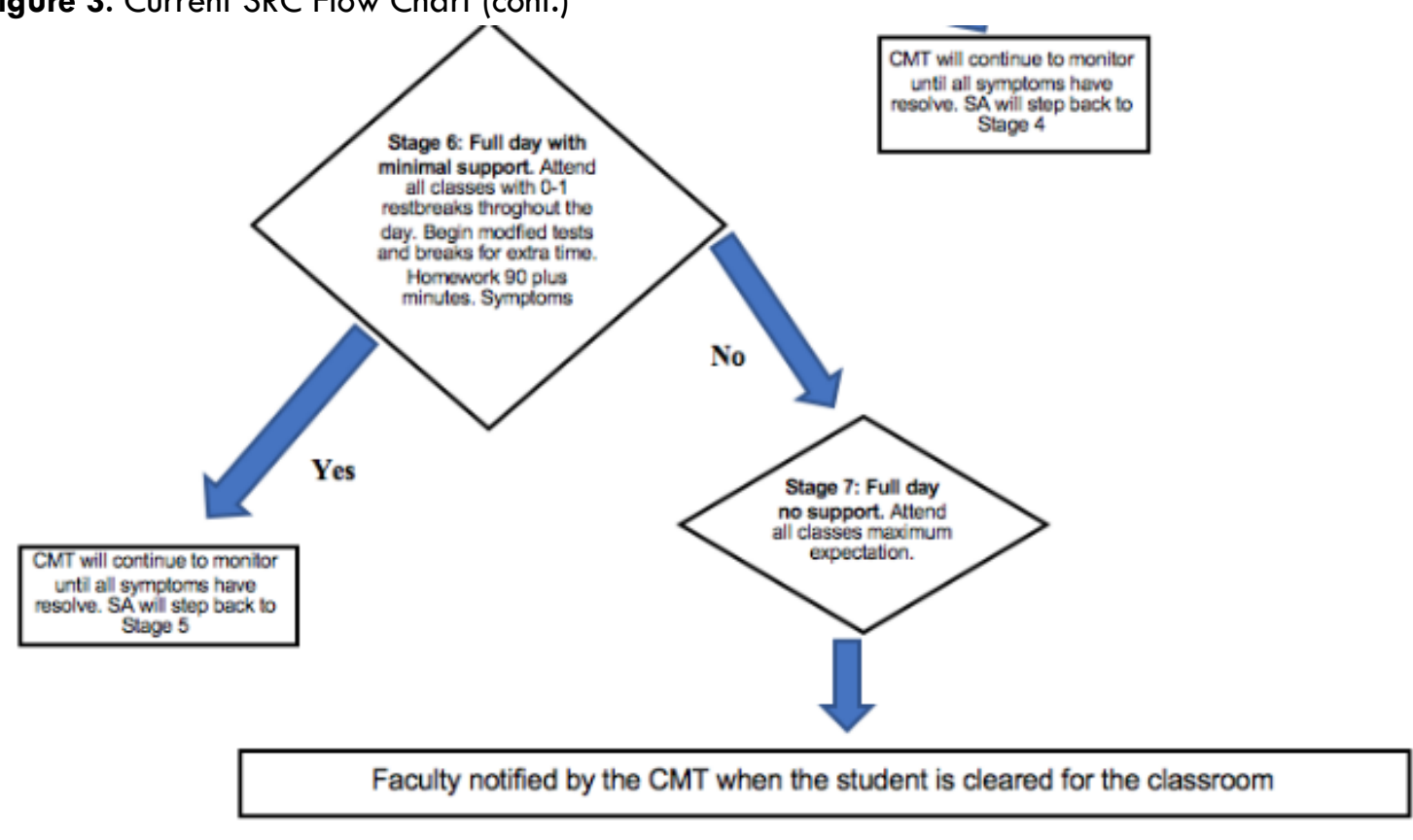

